\title{
Chris Mack Takes Over as JM³ Editor-in-Chief in 2012
}

Starting in 2012, Dr. Chris A. Mack will succeed me as editorin-chief of $\mathrm{JM}^{3}$, when my term comes to an end. Most lithographers know Chris through the lithography simulation software PROLITH. I also came to know Chris through the very first version of PROLITH. I remember listening to this new lithographer presenting lithography simulation software that could run on a personal computer. That was in the 1980s when the PC was just getting a foothold and lithography simulation could only run on mainframe computers. Even though the capability of PROLITH could not be compared to mainframe programs at that time, the PC compatibility excited the crowd. Better yet, floppy disks of the software were freely distributed by Chris after his presentation at the SPIE Microlithography Symposium. During that time he was working for the U.S. Department of Defense (DoD). Any software developed with taxpayer money had to be freely available for the public. Similarly, the legendary SPLAT and SAMPLE lithography simulation software programs developed at the University of California, Berkeley by Prof. Andy Neureuther and his students were also free. The only charge was for the administrative cost of the media.

PROLITH took off, with version after version being developed, and Chris's career progressed likewise. He finally resigned from the DoD and founded FINLE Technologies in 1990 to develop and market PROLITH. We saw it becoming one of the dominating lithography software programs in the industry and the price moved up substantially according to its functions and market share. FINLE was acquired by KLATencor in 2000, and Chris became vice president of lithography technology for KLA-Tencor, leaving his position as president and CTO of FINLE. Despite these business ventures, Chris managed to stay technical, publishing oral and written papers and lecturing for university courses and conference short courses. In fact, his products and customers exposed him to a large variety of lithography areas that helped to establish him as a well-recognized expert. No wonder he calls himself a lithography guru.
Chris has been an associate editor of $\mathrm{JM}^{3}$ since its inauguration. He received bachelor of science degrees in physics, chemistry, electrical engineering, and chemical engineering from Rose-Hulman Institute of Technology in 1982, a master of science degree in electrical engineering from the University of Maryland in 1989, and a PhD in chemical engineering from the University of Texas at Austin in 1998. In 2003 he received the SEMI Award for North America for his efforts in lithography simulation and education. He became a fellow of SPIE in 2006 and a fellow of IEEE in 2010. In 2009 he received the SPIE Frits Zernike Award for Microlithography. He is an adjunct faculty member at the University of Texas at Austin and spent the fall 2006 semester as a visiting professor at the University of Notre Dame. He has completed a comprehensive graduate-level textbook on optical lithography, Fundamental Principles of Optical Lithography, published in late 2007. Currently, he writes, teaches, and consults on the field of semiconductor microlithography in Austin, Texas, where he lives with his wife Susan and their daughters Sarah and Anna.

Chris has the time, passion, and reputation to guide $\mathrm{JM}^{3}$ through the coming years. As founding editor-in-chief, I have great confidence in passing the torch to Chris and am certain that he will continue our efforts to make $\mathrm{JM}^{3}$ a world-class journal on micro/nanolithography, MEMS, and MOEMS.

Happy reading!

Burn J. Lin

Editor-in-Chief

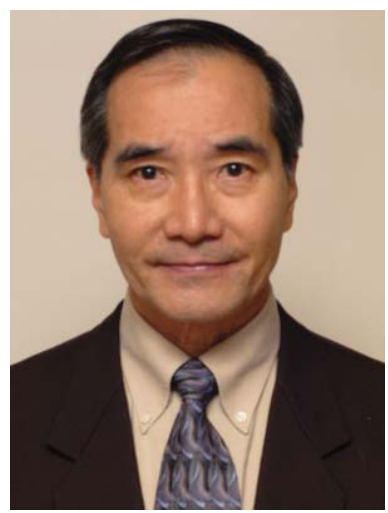

